\title{
FIT AND HEALTHY IN MIDDLE ADULTHOOD - DO FITMESS LEVELS MAKE A DIFFERENCE
}

\author{
Katja Klemm, ${ }^{1, A, B, C, D}$ Walter Brehm, ${ }^{2, A, D}$ Steffen Schmidt, ${ }^{1, B, C}$ \\ Ine Lucia De Clerck, ${ }^{3, A, B, D}$ Klaus Bös ${ }^{1, A, B, C, D}$ \\ ${ }^{1}$ Institute of Sports and Sports Science (IfSS), Karlsruhe Institute of Technology (KIT), Germany \\ ${ }^{2}$ Department of Sport Science, University of Bayreuth, Germany \\ ${ }^{3}$ Research \& Development in Health \& Care, Artevelde University of Applied Sciences, Belgium

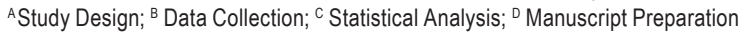

\section{Address for corpespondence:} \\ Katja Klemm \\ Engler-Bunte-Ring 15, 76131 Karlsruhe, Germany \\ E-mail: katja.klemm@kit.edu
}

\begin{abstract}
Ahstract Strong evidence exists that fitness is a physical health resource, which serves to protect one's health. There is still uncertainty about which fitness level provides the best health outcome and which measurements can be used for analyzing this question. This cross-sectional study analyzed 462 (64.07\% female) German middle-aged adults regarding their fitness status, physical activity (Non-Exercise test), body composition (Body Mass Index) and heart-related health status. Motor tests were used to measure the health-related fitness status. The heart-related health status was surveyed by questionnaire and diagnosis was done in part by a physician. Relationships between risk factors and fitness factors are visible during the correlative analysis. They are substantially more visible in the differentiation of people with and without risks. People with low fitness show noticeable risks in activity, Body Mass Index and heart-related health. People with high fitness show health resources for activity, Body Mass Index and heart-related health. This study points out that all fitness dimensions influence one's heart-related health in a positive way. Fitness is measured objectively and includes all health-related fitness dimensions such as endurance, strength, coordination and flexibility. Apart from this standardization, we ask for more longitudinal studies and more objective health measurements.
\end{abstract}

Key worlls fitness, health, middle age, physical activity, heart-related risk

\section{Introduction}

Fitness is a popular term and everyone wants to be "fit". However, the understanding of fitness is different. Subjective perceptions can be to feel good or to feel strong, to have energy or to have strength. It is common that "being fit" is mostly associated with "being healthy". What does it mean to be fit or to be healthy? Which fitness level do people need to reach to be healthy? 
In this paper, the clarification of terms and their relationships is done based on the model of health-related fitness (HRF) (see Figure 1) by C. Bouchard, S.N. Blair and W.L. Haskell (2012).

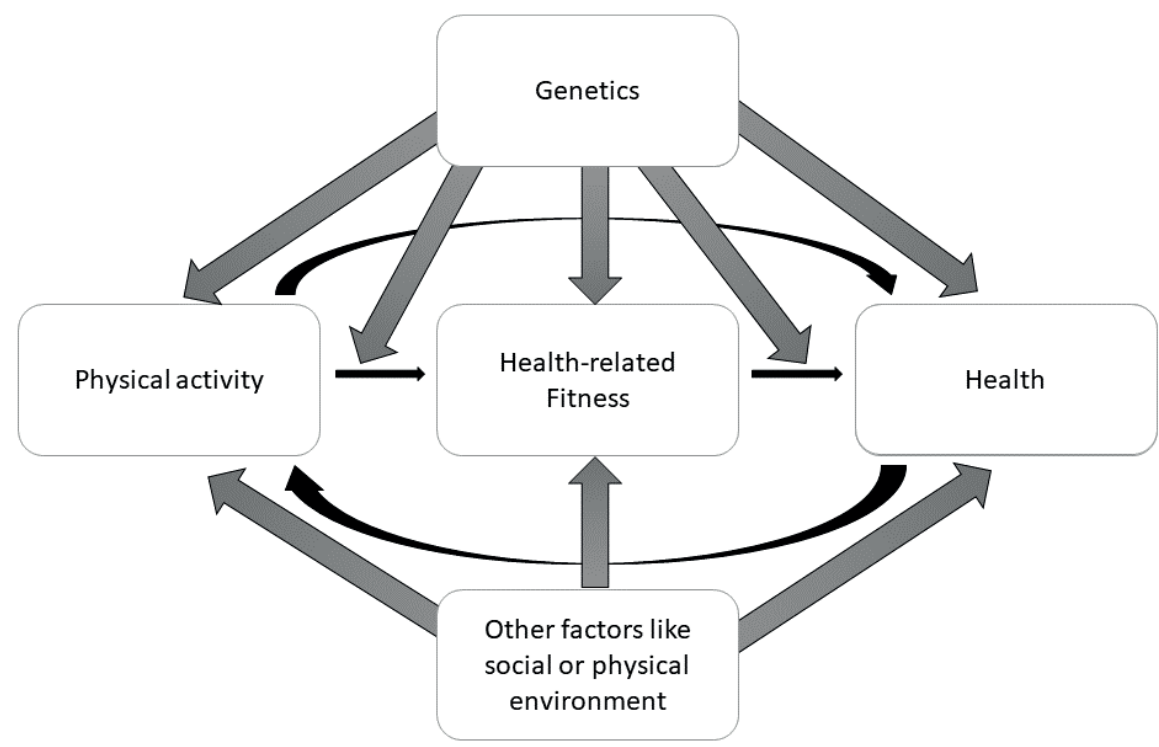

Figure 1. Model of health-related fitness

Source: own illustration based on Bouchard et al. (2012).

Defining health is challenging due to the flexible definitions of disease and the progress in treating them and developing resources (Hardman, Stensel, 2009). The World Health Organization (WHO) (1986) defines health as a concept emphasizing social and personal resources as well as physical capacities. A. Antonovsky (1996) adds that physical, social and psychological dimensions are characterized on a continuum with positive and negative poles. Hence, health is not just the absence of disease, but the capacity to enjoy life and to withstand challenges (Bouchard, Shephard, 1994). In their study over 20 years ago, P. Becker et al. examined parameters influencing health and named them "health-related variables" (Becker, Bös, Opper, Woll, Wustmans, 1996). Existing current literature in the context of fitness and activity concentrates mostly either on the understanding of health in the physical context (mortality, body composition, blood values etc.) (Warburton, 2006) or on the understanding of health in a psychological context (well-being, enjoying life) (Bize, Johnson, Plotnikoff, 2007; Olivares, Gusi, Prieto, Hernandez-Mocholi, 2011). This paper concentrates on aspects of the physical context, in particular the heartrelated health of a person.

According to Figure 1, Physical Activity (PA), HRF, genetics and other factors, such as the individual environment, directly influence health. PA is every bodily movement produced by the skeletal muscle that results in energy expenditure (Caspersen, Powell, Christenson, 1985). Physical exercise, in turn, is a subcategory of PA and describes planned and structured activity (Caspersen et al., 1985). In fact, it aims to maintain or improve components of physical fitness (PF). 
There is strong evidence that fitness is a physical health resource which serves to protect one's health (Blair, Cheng, Holder, 2001; Woll, 2006). HRF is a component of PF, which evolved out of the examined relationship among fitness, health and PA (Malmberg et al., 2002; Suni et al., 1998). PA favorably affects HRF, whereas sedentary behavior unfavorably affects it (Bouchard et al., 2012). The most important components of HRF are cardiorespiratory fitness (endurance), muscular fitness (strength), coordination and flexibility (Bös, Mechling, 1985; Caspersen et al., 1985; Oja, 1991; Samitz, Baron, 2002; Suni et al., 1998). Sometimes other components, particularly body composition and posture, are added to this health-related understanding of fitness (Bös, Mechling, 1985; Caspersen et al., 1985; Oja, 1991; Samitz, Baron, 2002; Suni et al., 1998).

Middle age, also called middle adulthood, is defined as the life period between early and late adulthood, including men and women aged 30 to 65 (Berk, 2017; Lademann, Kolip, Deitermann, Bucksch, Schwarze, 2005). Research groups in fitness/activity context focus mostly on men and women aged 40 to 59 (Sandvik et al., 1993; Zadworna-Cieślak, Ogińska-Bulik, 2018). We adopt this definition for further possibilities of comparison.

In middle adulthood, people often have their first contact to age-related health problems. Decrease of muscle mass and bone density, decline in physical capacities, increase of fat mass, sleep complaints, increase in frailty, chronic and cardiovascular diseases characterize typical symptoms of adults in this life period. People at this age experience a midlife crisis or menopause and change roles from caring for children to caring for parents (Berk, 2017; Dishman et al., 2015; Hardman, Stensel, 2009; Lademann et al., 2005; National Center for Health Statistics, 2009; Rockwood, Song, Mitnitski, 2011; Zadworna-Cieślak, Ogińska-Bulik, 2018).

In the scientific community, it is strongly evident that fitness is a meaningful predictor for health (Blair, Church, 2004; Blair et al., 1989; Bös, Tittlbach, Woll, Suni, Oja, 2012; Brehm, Sygusch, Tittlbach, 2008; Tittlbach, Jekauc, Schmidt, Woll, Bös, 2017; Williams, 2001). Having a close look at the literature of the last two decades, many reviews investigated if PA in middle adulthood influences different factors of health (Bize et al., 2007; Blair et al., 2001; Bucksch, Schlicht, 2006; DiPietro, 2001; Kokkinos, 2012; Reiner, Niermann, Jekauc, Woll, 2013; Trost, Owen, Bauman, Sallis, Brown, 2002; Vuori, 1998; Wagner et al., 2004; Warburton, 2006). Some reviews addressed the question of which dose of PA has the highest impact (Haskell, 1994; Lee, Skerrett, 2001; Oja, 2001; Warburton, 2006) or which health outcomes were improved the most by PA (Bucksch, Schlicht, 2006; HHS, 1996; Kokkinos, 2012; Reiner et al., 2013; Warburton, 2006). Nevertheless, up to now, just a few studies exist that examined the coherence of fitness and health in a longitudinal way (Blair et al., 1995; Sandvik et al., 1993; Schmidt, Tittlbach, Bös, Woll, 2017). Recently, P. Kokkinos et al. (2017) demanded for extending research with objectively measured aspects of fitness, such as using valid and reliable tests, like the treadmill test for measuring cardiorespiratory fitness. Research groups of S.N. Blair (1995) and L. Sandvik (1993) assessed PF using a treadmill test and bicycle ergometer respectively. S. Schmidt et al. (2017) assessed health during a laborious health examination conducted by a practicing physician and fitness with 13 motor performance tests in four motor dimensions: cardiorespiratory fitness, strength, coordination and flexibility. Results of this longitudinal study are various; central to the purpose of this paper is that health limitations rise with increasing age and with decreasing PF.

Among others, the research groups of L. Sandvik (1993), J. Myers (2004) and S.N. Blair (1989) analyzed the effect among cardiorespiratory fitness and mortality risk, according to different stages of fitness. L. Sandvik et al. and J. Myers et al. divided their sample in quartiles, according to the result of an exercise test (cycle ergometer or treadmill test). S.N. Blair et al. split their sample into quintiles, according to the result of a treadmill test. All three studies reported an inverse reduction of mortality rates when the fitness level increased. L. Sandvik et al. executed 
a follow-up of middle-aged men after 16 years. The highest fitness quartile had a relative risk of mortality of 0.54 in comparison to the lowest fitness quartile, though results were adjusted for age, smoking, serum lipids, blood pressure, resting heart rate, vital capacity, Body Mass Index (BMI), PA level and glucose tolerance. J. Myers et al. executed a follow-up study with men in middle age, too. The highest fitness quartile displays lowest age-adjusted mortality risk in comparison to the lowest quartile (hazard ratio $=0.28$ ). S.N. Blair et al. executed a follow-up of around eight years, but with middle-aged men and women. For both sexes, relative risk (with highest quintile as reference with 1.0) decreased from 1.0 to 3.44 for men and to 4.65 for women. Further studies (Blair et al., 1995; Kampert, Blair, Barlow, Kohl III, 1996; Katzmarzyk, Church, Blair, 2004) differentiate just two groups: fit and unfit, but they confirm the findings of Sandvik, Myers and Blair.

Considering all of this evidence, it seems that a lot has been done so far with regards to examining the construct of HRF, PA and health. However, most of these studies focus on cardiorespiratory fitness. Still, there is a need of further research, including objective measures of other fitness aspects such as strength, coordination and flexibility. This is we want our study to complement, while using objective measures in health-related fitness and heart-related health for our target group of middle-aged adults.

The central aim of this study is to compare middle-aged adults' risks in activity, body composition and heartrelated health with their HRF level. Related to this, the research question of this study is in which way the level of HRF influences middle age people's health.

Derived from the afore mentioned studies, the following working hypotheses are proposed:

1. A higher fitness level relates to a higher activity level.

2. A higher fitness level relates to better results in BMI.

3. A higher fitness level relates to a lower number of heart-related health issues.

\section{Methods}

\section{Sample}

For the last three years (2015-2017), data has been recorded from different executed studies of our research group in Germany. This data has now been analyzed for the above-named research question.

The sample includes 462 participants ( $64.07 \%$ female) with an average age of 50.28 years (SD $=4.92)$ and an average activity level of $3.69\left(\mathrm{SD}=1.32\right.$ ), according to the $\mathrm{N}$-Ex classification ${ }^{1}$. The average BMI value is 25.34 $(S D=4.17)$ and around $9 \%$ of the sample suffers from heart-related health issues.

All participants first answered different questionnaires including the Non-Exercise questionnaire (N-Ex) (Jurca et al., 2005) as an activity questionnaire and the Physical Activity Readiness Questionnaire (PAR-Q) ${ }^{2}$ (Chisholm, Collis, Kulak, Davenport, Gruber, 1975) as a health questionnaire. A physician partly $(n=250)$ diagnosed participants regarding different health issues. Secondly, they performed several motor tests in the dimensions of endurance, strength, coordination and flexibility without a specific order. Additionally, they were measured in height, weight and waist circumference.

\footnotetext{
${ }^{1}$ Non-Exercise questionnaire from 1 = "no physical activity" to 5 = "more than three hours physical active per week"; see Jurca et al. (2005).

${ }^{2}$ For a detailed description and the handling of the PAR-Q at the EFB see the Handbook for Instructors (Bös, Brehm, Klemm, Schreck, Pauly, 2017).
} 


\section{Methodology}

The sample was analyzed for the following parameters: motor test results, body composition, activity and health status. In detail, the analysis integrates one motor test per dimension. For endurance, a step and walking test are taken into account. Both tests are well validated (Aadahl, Zacho, Linneberg, Thuesen, Jørgensen, 2013; Laukkanen, Oja, Pasanen, Vuori, 1993). R.M.T. Laukkanen et al. for the 2-km walking test and M. Aadahl et al. for the step test developed algorithms for estimating the $\mathrm{VO}_{2}$ max. Further motor tests were a push-up test for strength (number of push-ups), a flamingo balance test for coordination (number of fails) and a sit \& reach test for flexibility (reaching length). All tests are well evaluated and used often (Klemm, Brehm, Bös, 2017; Tittlbach et al., 2017). $\mathrm{BMI}$ represents the body composition ${ }^{3}$. BMI is classified in a bivariate parameter with either a healthy BMI from 18.5 to $24.9(0)$ and an unhealthy BMI starting from 25.0 (1). People who were underweight were negated because of different health risks and low participant numbers $(n=7)$.

PA is displayed through the N-Ex test (questionnaire from $1=$ "no physical activity" to $5=$ "more than three hours physically active per week") (Jurca et al., 2005). PA in this context is described as "at least moderate intensity, that means with substantial increases in breathing and heart rate" (Bös et al., 2017; Jurca et al., 2005). Activity is calculated into a bivariate parameter as well. According to WHO recommendations (WHO, 2010) and the possible threshold the N-Ex allows, people with an activity level below one hour per week were classified with "1" and people with at least one hour per week of activity with " 0 ".

Health is measured either by self-assessed health questionnaire and/or by diagnosis from a physician. The physician was not available at all test days. That is why 212 participants just answered the self-assessed health questionnaire. To have the best possible display of heart-related health we matched the following questions of the self-assessed questionnaire with the cardiovascular diagnosis of the physician:

1. Has your doctor ever said that you have a heart condition and that you should only do physical activity recommended by a doctor?

2. Do you feel pain in your chest when you do physical activity?

3. In the past month, have you had chest pain when you were not doing physical activity?

This diagnosis rated the cardiovascular status of the participant in five categories: (1) chronical manifest; (2) chronical beginning; (3) acute long-term; (4) acute short-term and (5) unremarkable healthy.

In summary, these questions were pooled to the bivariate parameter "heart-related health" with either no heart problems (0) or any heart problems (1). Fitness and activity are identified as heart disease risk factors through studies and meta-analysis in the last few years (Blair et al., 2001; Williams, 2001). Mostly, activity was focused. In our study, the focus lies on fitness including all relevant fitness dimensions.

\section{Statistics}

Statistical analysis is separated for sex, but not for age. Regarding the analyzed fitness parameters, men and women display great significant differences. The chosen age group of middle-aged people display low mean value differences. Therefore, a comparison regarding age for fitness, activity and BMI was neglected.

\footnotetext{
${ }^{3}$ Full descriptions and scientific background of every single test item can be found in the Handbook for instructors (Bös et al., 2017).
} 
First, correlations were calculated. Second, extreme value comparisons were executed due to an assumed limited linear correlation. People at risk concerning activity (less than one hour per week of PA), body composition $(B M I \geq 25.0)$ and coronary risks (acute heart issues) were compared with people without risk regarding fitness in the dimensions of endurance, strength, coordination and flexibility. It is anticipated that both groups display great differences in their fitness.

Hypotheses were proven through 1) examining a correlation matrix; 2) examining mean values of extreme groups (with risk, without risk).

The significance level is set for .05 ("significant $\leq 0.05$, **highly significant $\leq 0.01$ ). Pearson's correlations are categorized as low $(r \geq 0.10)$, medium $(r \geq 0.30)$ or high $(r \geq 0.50)$ (Cohen, 1992). Partial eta square $\left(n^{2}\right)$ is as well categorized after J. Cohen (1992) to low $\left(\eta^{2} \geq 0.01\right)$, medium $\left(\eta^{2} \geq 0.06\right)$ or high $\left(\eta^{2} \geq 0.14\right)$. Calculations are done with IBM SPSS Version 24. All study participants agreed in writing to the usage of the anonymized data for scientific calculations and publications.

\section{Results}

Correlative Relationships between fitness and risk factors:

Table 1. Correlations between the fitness dimensions and activity, BMI and heart-related health

\begin{tabular}{llccccc} 
& \multicolumn{3}{c}{ Men $(\mathrm{n}=166)$} & \multicolumn{3}{c}{ Women $(\mathrm{n}=296)$} \\
\cline { 2 - 7 } & $\mathrm{N}-\mathrm{Ex}$ & $\mathrm{BMI}$ & Heart & $\mathrm{N}$-Ex & BMI & Heart \\
\hline Endurance & $0.46^{* *}$ & $-0.39^{* *}$ & $-0.19^{*}$ & $0.30^{* *}$ & $-0.28^{* *}$ & $-0.23^{* *}$ \\
Strength & $0.25^{* *}$ & $-0.17^{*}$ & $-0.26^{* *}$ & $0.28^{* *}$ & $-0.28^{* *}$ & $-0.21^{* *}$ \\
Coordination & $0.21^{* *}$ & $-0.33^{* *}$ & $-0.17^{*}$ & $0.26^{* *}$ & $-0.38^{* *}$ & $-0.29^{* *}$ \\
Flexibility & $0.19^{*}$ & $-0.23^{* *}$ & $-0.18^{*}$ & $0.22^{* *}$ & $-0.28^{* *}$ & $-0.19^{* *}$ \\
Fitness overall & $0.35^{* *}$ & $-0.36^{* *}$ & $-0.28^{* *}$ & $0.29^{* *}$ & $-0.37^{* *}$ & $-0.25^{* *}$
\end{tabular}

Table 1 displays the significant correlations between activity, BMI, heart-related health and all fitness dimensions, which spread from 0.17 to 0.46 . Explanation of variance ranges between $3 \%$ and $21 \%$.

The highest correlations are visible between activity and fitness, especially at endurance (males $=0.46$, females $=0.30$ ). Almost the same values display the correlation between BMI and all fitness dimensions. In particular, endurance shows highest correlation for men and coordination for women in terms of BMI. Correlations between health index and fitness is lower, but for fitness overall, correlations of 0.28 (men) and 0.25 (women) occur.

All three working hypotheses can be verified, though relations are somehow low. The question now is if correlations between activity, BMI, health index and fitness become clearer through comparing extreme groups (with risk, without risk). 
Extreme groups comparison (with risk, without risk) regarding fitness:

1. Activity and fitness

Table 2. Extreme groups comparison of activity regarding the fitness dimensions in male participants

\begin{tabular}{|c|c|c|c|c|c|c|}
\hline & $n$ & Endurance & Strength & Coordination & Flexibility & Overall fitness \\
\hline Q1 (M(SD)) & $31-36$ & $0.58(0.50)$ & $0.36(0.49)$ & $0.38(0.49)$ & $0.38(0.49)$ & $0.48(0.51)$ \\
\hline \multirow[t]{4}{*}{ Q5 (M(SD)) } & $24-44$ & $0.10(0.31)$ & $0.16(0.37)$ & $0.23(0.42)$ & $0.18(0.39)$ & $0.08(0.28)$ \\
\hline & $\mathrm{F}$ & 20.277 & 3.459 & 1.965 & 3.152 & 12.012 \\
\hline & $P$ & 0.000 & 0.067 & 0.165 & 0.081 & 0.001 \\
\hline & $\eta^{2}$ & 0.26 & 0.05 & 0.03 & 0.05 & 0.19 \\
\hline
\end{tabular}

Table 3. Extreme groups comparison of activity regarding the fitness dimensions in female participants

\begin{tabular}{|c|c|c|c|c|c|c|}
\hline & $\mathrm{n}$ & Endurance & Strength & Coordination & Flexibility & Overall fitness \\
\hline Q1 (M(SD)) & $48-66$ & $0.40(0.49)$ & $0.42(0.50)$ & $0.52(0.50)$ & $0.38(0.49)$ & $0.43(0.50)$ \\
\hline \multirow[t]{4}{*}{ Q5 (M(SD)) } & $46-85$ & $0.11(0.32)$ & $0.17(0.38)$ & $0.26(0.44)$ & $0.18(0.39)$ & $0.15(0.36)$ \\
\hline & $\mathrm{F}$ & 12.750 & 8.640 & 9.753 & 5.297 & 10.419 \\
\hline & $P$ & 0.001 & 0.004 & 0.002 & 0.023 & 0.002 \\
\hline & $\eta^{2}$ & 0.11 & 0.07 & 0.07 & 0.05 & 0.09 \\
\hline
\end{tabular}

Activity displays the results of the N-Ex questionnaire. People at risk in activity (Q1) are defined as less than one hour active per week (less than $400 \mathrm{kcal}$ energy expenditure per week). The differences between people with and without risk are all significant and partly very high (Tables 2 and 3 ). $\eta^{2}$ varies from 0.03 to 0.26 for men and from 0.05 to 0.11 for women. The greatest differences show the endurance for men and women. The smallest differences occur for men regarding coordination and for women regarding flexibility.

Mean values are scaled $0-1$, which allows a direct interpretation with a percentile score. As displayed in Tables 2 and 3, 36-58\% of men and 38-43\% of women in Q1 have the risk factor inactivity. In the fit group of Q5, only $8-23 \%$ of men and $11-26 \%$ of women have the risk factor inactivity.

This result is clear and confirms working hypothesis 1. Low fit people (Q1) more often display the risk factor inactivity than high fit people do.

2. Body composition and fitness

Table 4. Extreme groups comparison of BMI regarding the fitness dimensions in male participants

\begin{tabular}{|c|c|c|c|c|c|c|}
\hline & $\mathrm{n}$ & Endurance & Strength & Coordination & Flexibility & Overall fitness \\
\hline Q1 (M(SD)) & $31-39$ & $0.84(0.37)$ & $0.72(0.46)$ & $0.78(0.42)$ & $0.75(0.44)$ & $0.81(0.39)$ \\
\hline \multirow[t]{4}{*}{ Q5 (M(SD)) } & $24-45$ & $0.27(0.45)$ & $0.47(0.51)$ & $0.38(0.49)$ & $0.50(0.51)$ & $0.21(0.41)$ \\
\hline & $\mathrm{F}$ & 29.259 & 4.747 & 14.229 & 4.089 & 32.052 \\
\hline & $P$ & 0.000 & 0.033 & 0.000 & 0.048 & 0.000 \\
\hline & $\eta^{2}$ & 0.33 & 0.06 & 0.16 & 0.06 & 0.37 \\
\hline
\end{tabular}


Table 5. Extreme groups comparison of BMI regarding the fitness dimensions in female participants

\begin{tabular}{|c|c|c|c|c|c|c|}
\hline & $n$ & Endurance & Strength & Coordination & Flexibility & Overall fitness \\
\hline Q1 (M(SD)) & $51-68$ & $0.48(0.50)$ & $0.63(0.49)$ & $0.67(0.48)$ & $0.48(0.50)$ & $0.53(0.50)$ \\
\hline \multirow[t]{4}{*}{ Q5 (M(SD)) } & $43-81$ & $0.15(0.36)$ & $0.24(0.43)$ & $0.17(0.38)$ & $0.19(0.39)$ & $0.09(0.29)$ \\
\hline & $\mathrm{F}$ & 14.352 & 18.752 & 43.299 & 11.670 & 26.584 \\
\hline & $P$ & 0.000 & 0.000 & 0.000 & 0.000 & 0.000 \\
\hline & $\eta^{2}$ & 0.12 & 0.15 & 0.25 & 0.09 & 0.20 \\
\hline
\end{tabular}

BMI represents the parameter for body composition. People at risk concerning body composition display a BMI of 25 or higher (according to WHO (2018) classification), and therewith have the risk of being overweight.

Differences between people with and without risk are all significant and partly very high (Tables 4 and 5). $\eta^{2}$ varies from 0.06 to 0.37 for men and from 0.09 to 0.25 for women. The greatest differences show the overall fitness for men and the coordination dimension for women. The smallest differences occur when looking at flexibility for men and women.

Mean values are scaled from $0-1$, which allows a direct interpretation with a percentile score.

According to table $4,19-26 \%$ of men in Q1 have the risk factor of being overweight, whereas $10-22 \%$ of women in Q1 display this risk factor (Table 5). In the fit group of Q5, $0-7 \%$ of men and $0-2 \%$ of women display the risk factor of being overweight.

This result is clear and confirms working hypothesis 2. Low fit people (Q1) more often have the risk factor of being overweight than high fit people (Q5) do.

3. Fitness and heart-related health

Table 6 . Extreme groups comparison of heart-related health regarding the fitness dimensions in male participants

\begin{tabular}{|c|c|c|c|c|c|c|}
\hline & $\mathrm{n}$ & Endurance & Strength & Coordination & Flexibility & Overall fitness \\
\hline Q1 (M(SD)) & $30-35$ & $0.23(0.43)$ & $0.26(0.44)$ & $0.19(0.40)$ & $0.26(0.44)$ & $0.25(0.44)$ \\
\hline \multirow[t]{4}{*}{ Q5 (M(SD)) } & $24-41$ & $0.03(0.18)$ & $0.03(0.18)$ & $0.05(0.22)$ & $0.07(0.27)$ & $0.00(0.00)$ \\
\hline & $\mathrm{F}$ & 5.495 & 7.243 & 3.999 & 3.513 & 7.714 \\
\hline & $P$ & 0.023 & 0.009 & 0.049 & 0.066 & 0.008 \\
\hline & $\eta^{2}$ & 0.09 & 0.10 & 0.05 & 0.06 & 0.13 \\
\hline
\end{tabular}

Table 7. Extreme groups comparison of heart-related health regarding the fitness dimensions in female participants

\begin{tabular}{|c|c|c|c|c|c|c|}
\hline & $n$ & Endurance & Strength & Coordination & Flexibility & Overall fitness \\
\hline Q1 (M(SD)) & $47-66$ & $0.16(0.37)$ & $0.17(0.38)$ & $0.22(0.42)$ & $0.10(0.31)$ & $0.15(0.36)$ \\
\hline \multirow[t]{4}{*}{ Q5 (M(SD)) } & $45-83$ & $0.00(0.00)$ & $0.00(0.00)$ & $0.01(0.11)$ & $0.02(0.14)$ & $0.00(0.00)$ \\
\hline & $\mathrm{F}$ & 10.332 & 9.374 & 19.248 & 3.395 & 8.213 \\
\hline & $P$ & 0.002 & 0.003 & 0.000 & 0.068 & 0.005 \\
\hline & $\eta^{2}$ & 0.09 & 0.08 & 0.13 & 0.03 & 0.07 \\
\hline
\end{tabular}


The heart-related health index includes coronary risks, built up through health questions and a diagnosis by a physician.

People with the risk factor for coronary risk have been classified by a physician or confirmed this risk with a self-assessed questionnaire.

The differences between people with and without risk are all significant and partly very high (Tables 6 and 7 ). $\eta^{2}$ varies from 0.03 to 0.26 for men and from 0.05 to 0.11 for women. The greatest differences show the endurance for men and women. The smallest differences occur regarding coordination for men and flexibility for women.

The mean values are scaled $0-1$, which allows a direct interpretation with a percentile score. As displayed in Tables 6 and 7, 19-26\% of men and $10-22 \%$ of women in Q1 have the risk factor coronary risk. In the fit group of $\mathrm{Q} 5$, only $0-7 \%$ of men and $0-2 \%$ of women have the risk factor coronary risk.

This result is clear and confirms working hypothesis 3. Low fit people (Q1) more often have coronary risk than high fit people (Q5) do.

\section{Discussion}

In summary, these results suggest first tendencies regarding the statement "fitter people are healthier people" and "the more fit the healthier". The above shown aspects of activity, body composition and heart-related health display mostly definite results for male and female subjects in relation to their fitness level. All working hypotheses can be confirmed.

The relationships between risk factors and fitness factors are visible during the correlative analysis. They are substantially more visible in the differentiation of people with and without risks. People with low fitness show noticeable risks in activity, BMI and heart-related health. People with high fitness show health resources for activity, $\mathrm{BMI}$ and heart-related health.

Activity (measured with N-Ex) and fitness show the clearest relationship. It is evident that especially the endurance dimension displays a strong relationship with fitness as well as the overall fitness value. Flexibility and activity display low relations. These results are in line with our expectations.

Body composition, measured with BMl, displays an expected clear relationship to the fitness dimensions. In those dimensions, where body mass needs to be moved (endurance dimension), overweight and obese people have considerable disadvantages. With female participants, coordinative-weak women are most overweight.

Heart-related health, measured with a questionnaire and a physician's diagnosis, displays clear relationships to fitness as well. The extreme value comparison suggests that there exists a threshold, and no strict linear relation between fitness and heart-related health exists. However, these results provide further support for people with high fitness to have better health chances.

It is unfortunate that the study includes some limitations. One source of weakness of this study is the sample bias. Though part of the sample was gathered in a random-control study, altogether subjects are on average fit and healthy. It is more striking that within this group of limited variances, those clear relationships between activity, body composition, heart-related health and fitness can be observed. It can be assumed that a more representative sample displays even clearer results.

Additionally, heart-related health in parts and activity are measured via questionnaires that subjects answered by themselves. Health is a broad construct as well (WHO, 1986). Body composition and heart-related health cover just a small part of this construct. Furthermore, self-assessed health and objectively diagnosed health are 
summed up for having one comparable parameter of health. Finally, yet importantly, this study presents crosssectional data. No statement can be made regarding the question if people with a higher coordination or flexibility level stay healthier over the long term, for example. As stated in the introduction, long-term studies focusing on cardiorespiratory endurance are numerous, but studies including the further health-related fitness dimensions are hard to find. A concrete next step needs to be a follow-up study regarding the motor dimensions displayed in our study. This point will be broadly described in the conclusion section.

This study points out that the level of fitness relates to one's health, and vice versa, in a positive way. Precisely, a higher fitness level in endurance, strength, coordination and flexibility relates to lower issues in heart-related health.

In sum, this study presents a tendency other research groups can confirm with their studies (Blair et al., 1989; Myers et al., 2004; Sandvik et al., 1993; Schmidt et al., 2017; Tittlbach et al., 2017). However, some challenges still remain and need to be focused on in further studies:

1. Assessing fitness objectively must be standardized. Not just assessing one aspect of PF like cardiorespiratory, which is evidently linked to health issues (Blair et al., 1989; Myers et al., 2004; Sandvik et al., 1993; Schmidt et al., 2017; Tittlbach et al., 2017). Measuring a broad fitness status including strength, coordination and flexibility can reveal further acknowledgments, which at this moment no one thought of in detail (Brehm, Wagner, Sygusch, Schönung, Hahn, 2005).

2. Having a clear standard for displaying fitness levels. Different authors structured fitness levels in quintiles, quartiles or according to the metabolic equivalent of task (MET). This study focused on quintiles according to percentile ranks. In general, all of these studies generated their reference group out of their own sample.

3. Assessing health with the help of practicing physicians or the like. This study only integrated BMI and heart-related health in part as objectively measured health aspects. However, the aim must be to have a fully objective measured health construct (Brehm et al., 2005).

4. There should be a demand to examine different specific health aspects that are influenced through an increase of PF. In completion to the first point, PF should be measured in different dimensions to have concrete recommendations for the practical field. In general, more studies should be executed as longitudinal studies to get statements regarding the dose-response-relationship.

5. Current studies focus on sedentary behavior as a higher risk factor than inactivity (Katzmarzyk, 2010; Thorp, Owen, Neuhaus, Dunstan, 2011). We could not examine this parameter with our sample. The focus of further research needs to have a full investigation of this risk factor as well.

This study is part of an overall evaluation of the EFB. This instrument aims to measure fitness and additional aspects such as body composition and posture to figure out individual recommendations for each participant. Every participant gets a certificate and seven pages of detailed feedback according to the results achieved. Based on this, they receive recommendations by their trainer e.g. for attending special sport classes (Klemm et al., 2017). This study confirms the assumption that a rise in PF, independent of people's fitness level, can improve the heart-related health of a person. This is the fundamental motivation of the EFB and its developers.

The most common reasons for Europeans to be physically active is to improve their health $(54 \%)$ or to improve their fitness (47\%) (European Commission, 2018). With the help of the EFB counselling, they get an idea of how to raise their fitness level and therewith to improve their health. Still, there is a need for more studies with standardized tests, broad samples and executed longitudinal style to tell participants what they will benefit from. For practical 
relevance it can be stated that an increase in structured and well-planed activity (Tittlbach et al., 2017) increases fitness and therewith increases health.

\section{Declarations}

\section{Ethics approval and consent to participate}

The ethics committee of the Karlsruhe Institute of Technology approved the study "Gesundheit zum Mitmachen", which display the participants in parts. The other data part is a data sample of European Fitness Badge (EFB) participants during a gymnastic festival in Berlin, Germany in 2017. Content of the EFB (test items and body measurements as height, weight and waist circumference) is similar to content of the study "Gesundheit zum Mitmachen" - that is why we presume that an approval by an ethic committee is not necessary. Adults chose voluntary if they want to participate and if they did, they read and signed a written informed consent including:

- data protection declaration according to EU data protection law,

- usage of the anonymized data for scientific calculations and publications,

- participation at one's own risk,

- the availability to stop the test anytime.

\section{Availability of data and material}

The datasets analyzed during the current study are not publicly available due to data protection but are available from the corresponding author on reasonable request.

\section{Competing interests}

The authors declare that they have no competing interests.

\section{Funding}

The EU Erasmus+ program from 2015 to 2019 funds the project "European Fitness Badge". Data is in parts generated through this project.

\section{Acknowledgements}

We want to thank Lee Hawkins very much for proofreading.

\section{References}

Aadahl, M., Zacho, M., Linneberg, A., Thuesen, B.H., Jørgensen, T. (2013). Comparison of the Danish step test and the watt-max test for estimation of maximal oxygen uptake: The Health2008 study. European Journal of Preventive Cardiology, 20 (6), $1088-1094$. DOI: $10.1177 / 2047487312462825$.

Antonovsky, A. (1996). The salutogenic model as a theory to guide health promotion. Health Promotion International, 11 (1), 11-18. DOI: 10.1093/heapro/11.1.11.

Becker, P., Bös, K., Opper, E., Woll, A., Wustmans, A. (1996). Vergleich von Hochgesunden, Normal-und Mindergesunden in gesundheitsrelevanten Variablen (GRV). Zeitschrift Für Gesundheitspsychologie, 4 (1), 55-76.

Berk, L. (2017). Development through the lifespan. Pearson Education India.

Bize, R., Johnson, J.A., Plotnikoff, R.C. (2007). Physical activity level and health-related quality of life in the general adult population: A systematic review. Preventive Medicine, 45 (6), 401-415. 
Blair, S.N., Cheng, Y., Holder, J.S. (2001). Is physical activity or physical fitness more important in defining health benefits? Medicine and Science in Sports and Exercise, 33 (6 Suppl), S379-99; discussion S419-20. DOI: 10.1097/00005768-200106001-00007.

Blair, S.N., Church, T.S. (2004). The Fitness, Obesity, and Health Equation: Is Physical Activity the Common Denominator? JAMA, 292 (10), 1232. DOI: 10.1001/jama.292.10.1232.

Blair, S.N., Kohl, H.W., Barlow, C.E., Paffenbarger, R.S., Gibbons, L.W., Macera, C.A. (1995). Changes in Physical Fitness and Allcause Mortality. Journal of Cardiopulmonary Rehabilitation, 15 (6), 449.

Blair, S.N., Kohl, H.W., Paffenbarger, R.S., Clark, D.G., Cooper, K.H., Gibbons, L.W. (1989). Physical fitness and all-cause mortality: A prospective study of healthy men and women. Jama, 262 (17), 2395-2401.

Bös, K., Brehm, W., Klemm, K., Schreck, M., Pauly, P. (2017). European Fitness Badge. Handbook for Instructors (Deutscher TurnerBund, Ed.). Retrieved from: https://fitness-badge.eu/wp-content/uploads/2017/03/EFB-Instructors-Handbook-EN.pdf.

Bös, K., Mechling, H. (1985). International Physical Performance Test Profile: For Boys and Girls from 9-17 Years" IPPTP 9-17". Internat. council of sport science and physical education (ICSSPE).

Bös, K., Tittlbach, S., Woll, A., Suni, J., Oja, P. (2012). FinGer - Physical activity, fitness and health - An international longitudinal study in Bad Schönborn and Tampere. International Sport Studies, 34 (2), 42-50.

Bouchard, C., Blair, S.N., Haskell, W.L. (2012). Physical activity and health. Human Kinetics.

Bouchard, C., Shephard, R.J. (1994). Physical activity, fitness, and health: The model and key concepts. In: C. Bouchard, R.J. Shephard, T. Stephens (eds), Physical activity, fitness, and health: International proceedings and consensus statement (pp. 7788). Champaign IL: Human Kinetics Publishers.

Brehm, W., Sygusch, R., Tittlbach, S. (2008). Gesundheits- und Fitness-Sport als Ressource für Erwachsene. Sport Und Gesundheit in Der Lebensspanne. Hamburg: Czwalina, pp. 31-47.

Brehm, W., Wagner, P., Sygusch, R., Schönung, A., Hahn, U. (2005). Health promotion by means of health sport-A framework and a controlled intervention study with sedentary adults. Scandinavian Journal of Medicine \& Science in Sports, 15 (1), 13-20.

Bucksch, J., Schlicht, W. (2006). Health-enhancing physical activity and the prevention of chronic diseases - An epidemiological review. Social and Preventive Medicine, 51 (5), 281.

Caspersen, C.J., Powell, K.E., Christenson, G.M. (1985). Physical activity, exercise, and physical fitness: Definitions and distinctions for health-related research. Public Health Reports, 100 (2), 126.

Chisholm, D.M., Collis, M.L., Kulak, L.L., Davenport, W., Gruber, N. (1975). Physical activity readiness. British Columbia Medical Journal, 17 (2), 375-378.

Cohen, J. (1992). A power primer. Psychological Bulletin, 112(1), 155.

DiPietro, L. (2001). Physical activity in aging: Changes in patterns and their relationship to health and function. The Journals of Gerontology Series A: Biological Sciences and Medical Sciences, 56 (suppl 2), 13-22.

Dishman, R.K., Sui, X., Church, T.S., Kline, C.E., Youngstedt, S.D., Blair, S.N. (2015). Decline in cardiorespiratory fitness and odds of incident sleep complaints. Medicine and Science in Sports and Exercise, 47 (5), 960.

European Commission (2018). Special Eurobarometer 472. Report Sport and Physical Activity. Retrieved from: https://ec.europa.eu/ sport/news/2018/new-eurobarometer-sport-and-physical-activity_en.

Hardman, A.E., Stensel, D.J. (2009). Physical activity and health: The evidence explained. London: Routledge.

Haskell, W.L. (1994). JB Wolffe Memorial Lecture. Health consequences of physical activity: Understanding and challenges regarding dose-response. Medicine and Science in Sports and Exercise, 26 (6), 649-660.

HHS (1996). Physical activity and health: A report of the Surgeon General. DIANE Publishing.

Jurca, R., Jackson, A.S., LaMonte, M.J., Morrow, J.R., Blair, S.N., Wareham, N.J., Haskell, W.L., van Mechelen, W., Church, T.S., Jakicic, J.M., Laukkanen, R. (2005). Assessing Cardiorespiratory Fitness Without Performing Exercise Testing. American Journal of Preventive Medicine, 29 (3), 185-193. DOI: 10.1016/j.amepre.2005.06.004.

Kampert, J.B., Blair, S.N., Barlow, C.E., Kohl III, H.W. (1996). Physical activity, physical fitness, and all-cause and cancer mortality: A prospective study of men and women. Annals of Epidemiology, 6 (5), 452-457.

Katzmarzyk, P.T. (2010). Physical activity, sedentary behavior, and health: Paradigm paralysis or paradigm shift? Diabetes, 59 (11), 2717-2725.

Katzmarzyk, P.T., Church, T.S., Blair, S.N. (2004). Cardiorespiratory fitness attenuates the effects of the metabolic syndrome on allcause and cardiovascular disease mortality in men. Archives of Internal Medicine, 164 (10), 1092-1097. 
Klemm, K., Brehm, W., Bös, K. (2017). The European Fitness Badge as a diagnostic instrument for the HEPA concept - Development and evaluation. Leipziger Sportwissenschaftliche Beiträge, 58 (2), 83-105.

Kokkinos, P. (2012). Physical activity, health benefits, and mortality risk. ISRN Cardiology.

Kokkinos, P., Myers, J., Franklin, B., Narayan, P., Lavie, C.J., Faselis, C. (2017). Cardiorespiratory Fitness and Health Outcomes: A Call to Standardize Fitness Categories. Mayo Clinic Proceedings, 93 (3), 333-336. DOI: 10.1016/j.mayocp.2017.10.011.

Lademann, J., Kolip, P., Deitermann, B., Bucksch, J., Schwarze, M. (2005). Schwerpunktbericht: Gesundheit von Frauen und Männern im mittleren Lebensalter. Berlin: Robert Koch-Institut.

Laukkanen, R.M.T., Oja, R., Pasanen, M.E., Vuori, I.M. (1993). Criterion validity of a two-kilometer walking test for predicting the maximal oxygen uptake of moderately to highly active middle-aged adults. Scandinavian Journal of Medicine \& Science in Sports, 3 (4), 267-272. DOI: 10.1111/j.1600-0838.1993.tb00393.x.

Lee, I.-M., Skerrett, P.J. (2001). Physical activity and all-cause mortality: What is the dose-response relation? Medicine \& Science in Sports \& Exercise, 33 (6), 459-471.

Malmberg, J.J., Miilunpalo, S.I., Vuori, I.M., Pasanen, M.E., Oja, P., Haapanen-Niemi, N.A. (2002). A health-related fitness and functional performance test battery for middle-aged and older adults: Feasibility and health-related content validity. Archives of Physical Medicine and Rehabilitation, 83 (5), 666-677.

Myers, J., Kaykha, A., George, S., Abella, J., Zaheer, N., Lear, S., Yamazaki, T., Froelicher, V. (2004). Fitness versus physical activity patterns in predicting mortality in men. The American Journal of Medicine, 117 (12), 912-918.

National Center for Health Statistics (2009). Health, United States, 2009: In Brief.

Oja, P. (2001). Dose response between total volume of physical activity and health and fitness. Medicine and Science in Sports and Exercise, 33 (6 Suppl), 428-437; discussion 452-453.

Oja, P. (1991). Elements and assessment of fitness in sport for all. Sport for All. Proceedings of the World Congress on Sport for All, Held in Tampere, Finland, 3-7 June 1990, 103-110.

Olivares, P.R., Gusi, N., Prieto, J., Hernandez-Mocholi, M.A. (2011). Fitness and health-related quality of life dimensions in communitydwelling middle aged and older adults. Health and Quality of Life Outcomes, 9 (1), 117. DOI: 10.1186/1477-7525-9-117.

Reiner, M., Niermann, C., Jekauc, D., Woll, A. (2013). Long-term health benefits of physical activity-a systematic review of longitudinal studies. BMC Public Health, 13 (1), 813.

Rockwood, K., Song, X., Mitnitski, A. (2011). Changes in relative fitness and frailty across the adult lifespan: Evidence from the Canadian National Population Health Survey. Canadian Medical Association Journal, 183 (8), E487-E494. DOI: 10.1503/cmaj.101271.

Samitz, G., Baron, R. (2002). Epidemiologie der körperlichen Aktivität. Körperliche Aktivität in Prävention Und Therapie. München.

Sandvik, L., Erikssen, J., Thaulow, E., Erikssen, G., Mundal, R., Rodahl, K. (1993). Physical fitness as a predictor of mortality among healthy, middle-aged Norwegian men. New England Journal of Medicine, 328 (8), 533-537.

Schmidt, S., Tittlbach, S., Bös, K., Woll, A. (2017). Different types of physical activity and fitness and health in adults: An 18-year longitudinal study. BioMed Research International, 2017.

Suni, J.H., Oja, P., Miilunpalo, S.I., Pasanen, M.E., Vuori, I.M., Bös, K. (1998). Health-related fitness test battery for adults: Associations with perceived health, mobility, and back function and symptoms. Archives of Physical Medicine and Rehabilitation, 79 (5), 559-569.

Thorp, A.A., Owen, N., Neuhaus, M., Dunstan, D.W. (2011). Sedentary behaviors and subsequent health outcomes in adults: A systematic review of longitudinal studies, 1996-2011. American Journal of Preventive Medicine, 41 (2), 207-215.

Tittlbach, S.A., Jekauc, D., Schmidt, S.C., Woll, A., Bös, K. (2017). The relationship between physical activity, fitness, physical complaints and BMI in German adults-results of a longitudinal study. European Journal of Sport Science, 17 (8), 1090-1099.

Trost, S.G., Owen, N., Bauman, A.E., Sallis, J.F., Brown, W. (2002). Correlates of adults' participation in physical activity: Review and update. Medicine \& Science in Sports \& Exercise, 34 (12), 1996-2001.

Vuori, I. (1998). Does physical activity enhance health? Patient Education and Counseling, 33, S95-S103.

Wagner, P., Brehm, W., Sygusch, R. (2004). The seven-sequence intervention: Sedentary adults on their way to fitness and health. Research in Sports Medicine, 12 (4), 265-282.

Warburton, D.E.R. (2006). Health benefits of physical activity: The evidence. Canadian Medical Association Journal, 174 (6), $801-809$. DOI: $10.1503 / \mathrm{cmaj} .051351$.

WHO (1986). The Ottawa Charter for Health Promotion.

WHO (2010). Global recommendations on physical activity for health. Retrieved from: http://www.ncbi.nlm.nih.gov/books/NBK305057. 
WHO (2018, September 24). Body mass index-BMI. Retrieved from: http://www.euro.who.int/en/health-topics/disease-prevention/ nutrition/a-healthy-lifestyle/body-mass-index-bmi.

Williams, P.T. (2001). Physical fitness and activity as separate heart disease risk factors: A meta-analysis. Medicine and Science in Sports and Exercise, 33 (5), 754.

Woll, A. (2006). Sportliche Aktivität, Fitness und Gesundheit im Lebenslauf: Eine internationale Längsschnittstudie. Schorndorf: Hofmann.

Zadworna-Cieślak, M., Ogińska-Bulik, N. (2018). Specificity of health-related behaviours in middle and late adulthood. Health Problems of Civilization, $12(1), 7-13$.

\title{
Legend/List of abbreviations
}

\author{
ANOVA - Analysis of Variance \\ $\mathrm{BMI}$ - Body Mass Index \\ EFB - European Fitness Badge \\ HRF - Health related fitness \\ KIT - Karlsruhe Institute of Technology \\ N-Ex - Non-Exercise Questionnaire \\ PA - Physical activity \\ PAR-Q - Physical Activity Readiness Questionnaire \\ PF - Physical fitness \\ $\mathrm{VO}_{2}$ max - Maximal oxygen consumption \\ WHO - World Health Organization \\ MET - Metabolic equivalent of task \\ $P$ - Significance \\ $\mathrm{R}$ - Correlation coefficient \\ $\mathrm{F}$ - F-value \\ $\eta^{2}-$ Eta square
}

Cite this anticle aS: Klemm, K., Brehm, W., Schmidt, S., De Clerck, I.L., Bös, K. (2020). Fit and Healthy in Middle Adulthood - Do Fitness Levels Make a Difference. Central European Journal of Sport Sciences and Medicine, 2 (30), 33-46. DOI: 10.18276/cej.2020.2-04. 